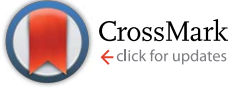

Cite this: J. Mater. Chem. A, 2015, 3, 10681

Received 26th March 2015 Accepted 14th April 2015

DOI: $10.1039 / c 5 t a 02205 c$

www.rsc.org/MaterialsA

\section{An extremely thin and robust interconnecting layer providing $76 \%$ fill factor in a tandem polymer solar cell architecture $\uparrow$}

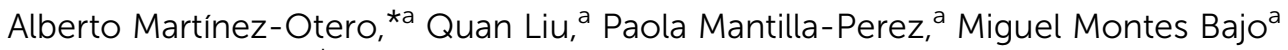 \\ and Jordi Martorell ${ }^{\mathrm{ab}}$
}

We report a thin and robust interconnecting layer (ICL) for polymer tandem solar cells. This ICL shows low absorption, good electrical contacts, large work function contrast and robustness. Its use yields tandem cells with a very high fill factor of $76 \%$, making this ICL a promising component of future highly efficient multijunction organic solar cells.

Bulk heterojunction polymer solar cells represent a promising technology which could be an important player in the future photovoltaic market due to their light weight, flexibility, semitransparency, low cost, and rapid energy payback time. ${ }^{1-6}$ The power conversion efficiency (PCE) of these polymer solar cells (PSCs) has been improved markedly in recent years ${ }^{7-10}$ and has now exceeded the milestone value of $10 \%,{ }^{11}$ which makes their industrialization to eventually commercialize them very promising. Moreover, by using the tandem concept, ${ }^{12}$ in which two or more subcells with complementary absorption spectra are stacked on top of each other and connected in series or parallel configuration, the PCE has been recently boosted to near $11 \%{ }^{13}$ Yang et al. and Brabec et al. recently published articles on organic single and tandem solar cells providing comprehensive reviews of different device structures and their working mechanisms. ${ }^{\mathbf{1 4 , 1 5}}$ Several studies foresee that there is still room for improvement. Dennler et al. predicted that organic tandem solar cells comprising two series-connected single junction cells would be able to reach a PCE of 15\% assuming 65\% fill factor (FF) and a constant External Quantum Efficiency (EQE) of $65 \% .{ }^{16}$ At present, those assumptions should be revised due to the fruitful and extensive research done in the last few years developing and optimizing buffer layers, donor materials and morphology. Recently, the same group predicted that organic

${ }^{a} I C F O$ - The Institute of Photonic Sciences, Av. Carl Friedrich Gauss, 3, 08860 Castelldefels, Barcelona, Spain. E-mail: a.martinez.otero@fz-juelich.de

${ }^{b}$ Departament de Física i Enginyeria Nuclear, Universitat Politècnica de Catalunya, o8222 Terrassa, Spain

$\dagger$ Electronic supplementary information (ESI) available. See DOI: $10.1039 / \mathrm{c} 5 \mathrm{ta} 02205 \mathrm{c}$ tandem devices can reach $21 \%$ efficiency assuming $80 \%$ EQE and $75 \%$ FF. ${ }^{17}$ Recently, Facchetti et al. reported a new donor polymer with high performance and a FF approaching values of their inorganic counterparts. ${ }^{18}$

The FF characterizes how "rectangular" the $J-V$ curve is and it represents how "difficult" or "easy" the photogenerated carriers can be extracted out of a photovoltaic device. This parameter is crucial to determine the performance of an organic solar cell together with the short circuit current density $\left(J_{\mathrm{sc}}\right)$ and the open-circuit voltage $\left(V_{\mathrm{oc}}\right)$. There are several factors that can influence the FF in a complex way, thus making the FF one of the least understood parameters among the ones determining the PCE. ${ }^{19}$

Commonly, in the fabrication of PSCs, several actions have shown to be beneficial for improving the $\mathrm{FF}$ and hence the efficiency like, for instance, improving the morphology ${ }^{20,21}$ or choosing appropriate buffer layers that can help diminish the contact resistance (reduce $R_{\mathrm{s}}$ ) or the current leakage (increase $\left.R_{\mathrm{sh}}\right)^{22}$

The buffer layers normally used as transporting layers in single junction solar cells also play another important role in multijunction solar cells as they are commonly part of the interconnecting layer (ICL). In tandem cells, the ICL serves as the charge recombination zone between the front and rear subcells; the ICL is vital in realizing high performance in tandem cells. ${ }^{23}$ Further requirements of the ICL are transparency and robustness to protect the underlying layers against damage from further solution processing of the rear subcell.

In this study, we report a novel and very thin ICL for multijunction configurations which provides FFs exceeding the ones of the single cells forming part of it and reaching values up to $76 \%$, never reported before in organic tandem solar cells to the best of our knowledge. Herein, we employed a $\mathrm{MoO}_{3} / \mathrm{Ag} / \mathrm{PFN}$ ICL layer, less than $20 \mathrm{~nm}$ thick, connecting two identical, inverted PTB7:PC71BM subcells in series. By using identical polymers in both subcells, one can overcome the decrease in $J_{\mathrm{sc}}$, FF, and ultimately PCE usually observed in single-junction cells when the thickness of the active layer is increased (see Fig. S1 
and $\mathrm{S} 2$, ESI $\dagger$ ). Indeed, a transfer matrix-based numerical determination of light absorption ${ }^{24,25}$ predicts a $14 \%$ increase in $J_{\mathrm{sc}}$ for the same polymer tandem cells relative to the optimal single-junction cell. The more commonly used PEDOT and $\mathrm{ZnO}$ ICL materials need thermal treatments that, despite efforts to decrease their temperature (see, for example, ref. 26), may still be detrimental to the bottom organic layers. Moreover, this ICL was used to have a thickness around $100 \mathrm{~nm}$ also to protect the underneath layers. Accordingly, in the device architecture described below, we employed thin layers of thermally evaporated $\mathrm{MoO}_{3}$ and the conjugated polyelectrolyte poly[9,9-bis $\left(3^{\prime}\right.$ ( $N, N$-dimethylamino)propyl)-2,7-fluorene]-alt-2,7-(9,9-dioctylfluorene)] (PFN) that can be deposited from solution without any further treatment. A thin Ag layer was evaporated between those two layers in order to favour the recombination of charges. In a recent report by Zheng et al., a similar ICL was employed and $0.5 \mathrm{~nm}$ of $\mathrm{Ag}$ were also used to establish ohmic contact. $^{11}$

It is also worth mentioning that only a few nanometers of PFN were necessary to obtain a good electrical contact and to protect the underlying layers from solvent penetration upon the deposition of the top subcell. As a result, the FF of the PTB7:PC71BM system was increased to a value of $76 \%$ in the tandem solar cells, never reported before to the best of our knowledge, while the PCE was increased from $7.3 \%$ in a single junction to $8.2 \%$ in our best tandem cells.

The tandem device structure used here is shown in Fig. 1 as well as the chemical structures of the PTB7 and PFN polymers and the device band structure. Two inverted cells with the same donor-acceptor materials were used, with the donor material being the well-known benzodithiophene derivative PTB7. ${ }^{27}$ The use of the same active blend in both subcells of a tandem cell has been considered in the past by You et al. Their research led to the same polymer tandem cell with $10.2 \%$ PCE. It is noticeable that, with a thick ICL, the FF they obtained was $65 \% .{ }^{28}$ Recently it has been shown by our group, for a four terminal configuration tandem device of the same material, that optical optimization of the field distribution is essential to obtain optimized light harvesting and to overcome the absorption capacity of the single layered cell (paper to be published) which is limited by the charge mobility in the active blend.
In contrast to other related studies, our tandem solar cell is composed of two subcells with different electron transporting layers (ETL). In the case of the front cell, a sol-gel solution of ZnO was used while for the rear cell, a PFN layer was deposited by spin coating.

In previous studies by our group, we were able to enhance the photovoltaic properties of the PTB7:PC71BM system using direct structures. ${ }^{5,24}$ In the current work, we fabricated inverted structures of the PTB7:PC71BM blend due to its better stability as there is no need to use the acidic PEDOT:PSS. ${ }^{29}$

We investigated the photovoltaic performance of single junction inverted PTB7:PC71BM PSCs with the following configurations, SJ1: glass/ITO/ZnO/PTB7:PC71BM/ $\mathrm{MoO}_{3} / \mathrm{Ag}$ and SJ2: glass/ITO/PFN/PTB7:PC71BM/ $\mathrm{MoO}_{3} / \mathrm{Ag}$. The single junction device of type SJ1 yields a $V_{\mathrm{oc}}=0.74 \mathrm{~V}$, a $J_{\mathrm{sc}}=14.3 \mathrm{~mA} \mathrm{~cm} \mathrm{~cm}^{-2}$ and a $\mathrm{FF}=69 \%$, resulting in a $\mathrm{PCE}=7.3 \%$ for a blend thickness of ca. $100 \mathrm{~nm}$ and a ZnO thickness of $35 \mathrm{~nm}$. The same PCE could be obtained for a device of type SJ2 which exhibited a $V_{\mathrm{oc}}=0.72 \mathrm{~V}$, $\mathrm{a} J_{\mathrm{sc}}=14.3 \mathrm{~mA} \mathrm{~cm}^{-2}$ and $\mathrm{aFF}=71 \%$ for a blend thickness of $c a$. $100 \mathrm{~nm}$ and a PFN thickness of $12 \mathrm{~nm}$. The blend composed of PTB7:PC71BM dissolved in chlorobenzene (CB) was deposited inside a glovebox to a thickness of $c a .100 \mathrm{~nm}$ in both cases. After a vacuum-drying period, the top electrode was evaporated on both devices, composed of $3 \mathrm{~nm}$ of $\mathrm{MoO}_{3}$ followed by $100 \mathrm{~nm}$ of Ag. After fabrication, all measurements were carried out in air without encapsulation and showed very similar results for both inverted structures. Device performances are summarized in Table 1. Some differences can be seen from the EQE data of both SJ1 and SJ2 devices, especially in the $400 \mathrm{~nm}$ to $600 \mathrm{~nm}$ region of the spectra (Fig. S3, ESI $\dagger$ ). In any case, the theoretical current densities extracted from the type SJ1 and SJ2 graphs are very similar between them and in accordance with the experimental results obtained. The EQE of the SJ2 device with PFN is rather featureless between $500 \mathrm{~nm}$ and $700 \mathrm{~nm}$ and shows an average value of $65 \%$. For the SJ1 device, with ZnO, peaks of $68 \%$ are observed at around $480 \mathrm{~nm}$ and in the $620 \mathrm{~nm}$ to 680 $\mathrm{nm}$ range. Around $400 \mathrm{~nm}$ and $550 \mathrm{~nm}$, the EQE values of the SJ1 device are lower than those of the PFN. Such differences arise mostly because of the dissimilar extinction coefficients of the transporting layers that modify the field distribution inside the device. a

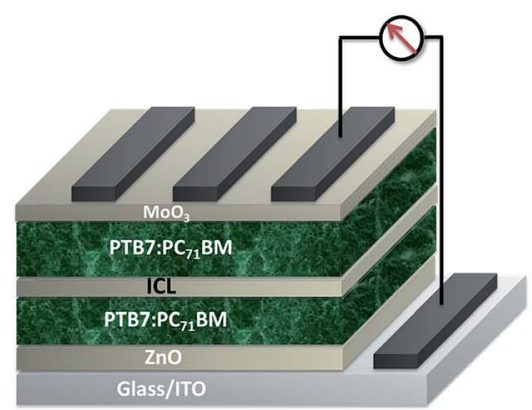

b

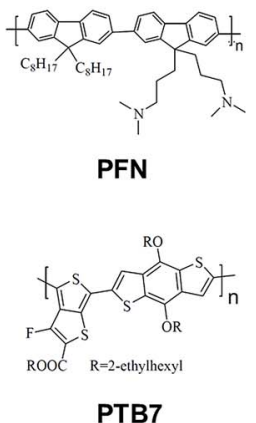

c

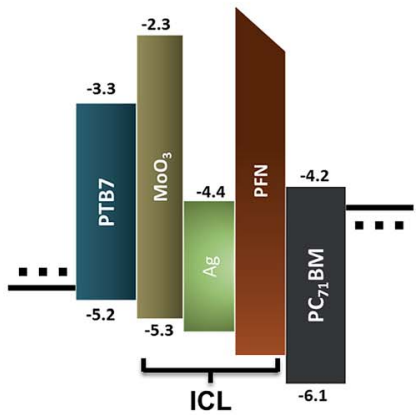

Fig. 1 (a) Device configuration of the tandem solar cell with a $\mathrm{MoO}_{3} / \mathrm{Ag} / \mathrm{PFN}$ interconnecting layer. (b) Chemical structure of the donor polymer PTB7 and conjugated polyelectrolyte PFN. (c) Schematic of the device band alignment. 
Table 1 Performance parameters of the single junction devices with different ETL and tandem devices with best efficiency and record FF. Single junction devices: glass/ITO/ETL/PTB7: $\mathrm{PC}_{71} \mathrm{BM} / \mathrm{MoO}_{3} / \mathrm{Ag}$ where $\mathrm{SJ} 1$ uses $\mathrm{ZnO}$ and SJ2 uses PFN as an ETL. Error bars are the standard deviation from the average values. Tandem devices: glass/ITO/ZnO/ PTB7:PC ${ }_{71} \mathrm{BM} / \mathrm{MoO}_{3} / \mathrm{Ag} / \mathrm{PFN} / \mathrm{PTB} 7: \mathrm{PC}_{71} \mathrm{BM} / \mathrm{MoO}_{3} / \mathrm{Ag}$. Average values ( \pm standard deviation) for the PCE and FF of the tandem cells are $8.0 \pm$ $0.2 \%$ and $73.8 \pm 1.5 \%$, respectively

\begin{tabular}{lllll}
\hline Device & $J_{\mathrm{sc}}\left[\mathrm{mA} \mathrm{cm}^{-2}\right]$ & $V_{\mathrm{oc}}[\mathrm{mV}]$ & PCE [\%] & FF [\%] \\
\hline SJ1 & $14.3 \pm 0.2$ & $741 \pm 0.003$ & $7.3 \pm 0.1$ & $69 \pm 0.4$ \\
SJ2 & $14.3 \pm 0.3$ & $723 \pm 0.002$ & $7.3 \pm 0.1$ & $71 \pm 1$ \\
T1 (best PCE) & 7.6 & 1480 & 8.2 & 73 \\
T2 (best FF) & 6.9 & 1477 & 7.8 & 76 \\
\hline
\end{tabular}

The tandem solar cell devices (type T) incorporating our new robust ICL show the following configuration: glass/ITO/ZnO/ PTB7:PC71BM/ $\mathrm{MoO}_{3} / \mathrm{Ag} / \mathrm{PFN} / \mathrm{PTB} 7: \mathrm{PC71BM} / \mathrm{MoO}_{3} / \mathrm{Ag}$.

It is well known that in a series-connected tandem solar cell, the photocurrents generated by the subcells have to be balanced to maximize the device performance. The optical simulation has been proven to be a powerful and reliable method to optimize the layer sequence as well as the layer thickness of tandem solar cells by calculating the photocurrents of both subcells. ${ }^{30}$ After the effective refractive index and thickness of the different layers were obtained, we implemented an optical simulation by means of the transfer matrix method to numerically determine the optimal device architecture following an inverted problemsolving procedure. More details about the optical model employed can be found in ref. 24 and 25 .

As a summary of this numerical study, in Fig. 2a, the dependence of $J_{\mathrm{sc}}$ on the thickness of the front and rear active layers of the tandem solar cell is shown. All the thicknesses of the other conforming layers in the tandem cell are kept constant. As observed in such a current map, having a front subcell with a thickness between $80 \mathrm{~nm}$ and $110 \mathrm{~nm}$ in combination with a rear subcell with a thickness between $90 \mathrm{~nm}$ and $130 \mathrm{~nm}$ leads to the optimal values of the current density. In contrast, lower current values arise when the front cell thickness reaches above $110 \mathrm{~nm}$, because the rear subcell current becomes a significant limiting factor. Lower current values also arise when the two subcells are below $90 \mathrm{~nm}$. The tendency observed in Fig. 2a shows that the current maxima can also be found for thicker rear subcells, above $130 \mathrm{~nm}$, but these cases are not desirable from the electrical point of view because of the lower performance of solar cells with increasing thickness. ${ }^{28}$ For this reason, we kept the rear subcell in our devices with thicknesses around $120 \mathrm{~nm}$. Even if they are not in the highest current region, we could achieve $7.6 \mathrm{~mA} \mathrm{~cm}{ }^{-2}$ for our best device, which approximates to the largest possible current of $7.8 \mathrm{~mA} \mathrm{~cm}^{-2}$ according to our simulations. The thicknesses of the active layers of this device could be measured by means of an atomic force microscope (AFM; see ESI Fig. S4†) showing values of $100 \mathrm{~nm}$ for the front subcell and $117 \mathrm{~nm}$ for the rear subcell. As indicated, a $J_{\mathrm{sc}}=7.6 \mathrm{~mA} \mathrm{~cm}{ }^{-2}$, a $V_{\mathrm{oc}}=1.48 \mathrm{~V}$ and a $\mathrm{FF}=73 \%$, resulting in a $\mathrm{PCE}=8.2 \%$, were obtained for our best performance tandem solar cell, and a $V_{\mathrm{oc}}=1.48 \mathrm{~V}$, a $J_{\mathrm{sc}}=6.9$ $\mathrm{mA} \mathrm{cm} \mathrm{cm}^{-2}$ and a $\mathrm{FF}=76 \%$, resulting in a $\mathrm{PCE}=7.8 \%$, were obtained for our best FF tandem solar cell with front and rear subcell thicknesses of $106 \mathrm{~nm}$ and $122 \mathrm{~nm}$, respectively.

For comparison, the experimentally determined $\mathrm{FF}$ values of PTB7:PC71BM single-junction cells were found to decrease with increased active layer thickness. For an active layer thickness equivalent to the sum of those of the $\mathrm{FF}=76 \%$ tandem cell subcells taken together (i.e. active layer thickness $228 \mathrm{~nm}$ ) it is found that $\mathrm{FF}<61 \%$. Therefore, the stacked tandem approach results in an FF increase of $\sim 25 \%$ (see Fig. S1b, ESI $\dagger$ ). The $J-V$ curves of the type $\mathrm{T}$ devices can be seen in Fig. 2 together with the SJ1 and SJ2 devices. Device performances are also summarized in Table 1.

In order to verify the robustness of our ICL, we used it in a tandem cell configuration composed of a front subcell of P3HT and a rear subcell of PTB7. Results can be seen in the ESI. $\dagger$ Even though the configuration was not optically or electrically optimized, the tandem cell presented a FF 8\% higher than the highest FF measured for any of the two subcells (Fig. S5, ESI $\dagger$ ).

A more in depth study was performed on our new ICL; in Fig. 3a, the measured extinction coefficient $(k)$ values of $\mathrm{MoO}_{3}$ and PFN are shown. The sol-gel processed ZnO used as an ETL in the front subcell is also included. Both $\mathrm{ZnO}$ and $\mathrm{MoO}_{3}$ have a

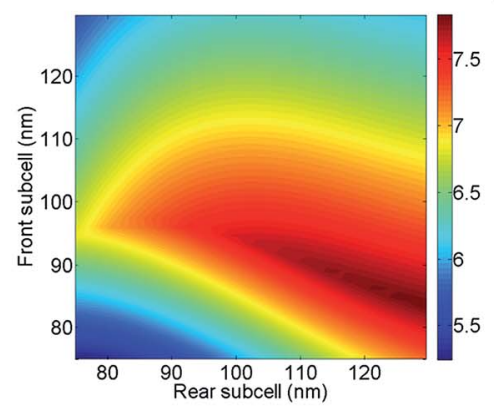

b

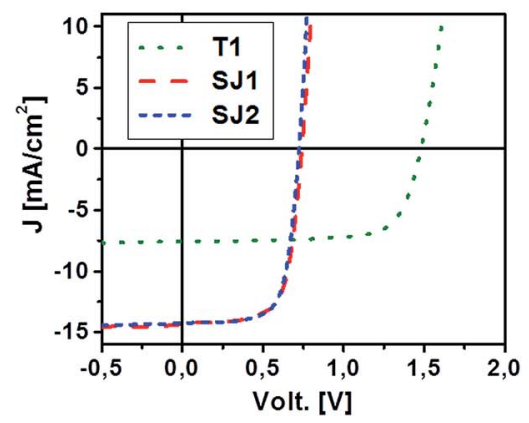

c

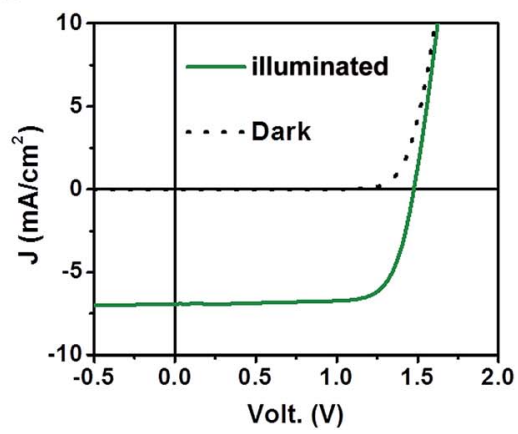

Fig. 2 (a) Simulated current density generated in a tandem solar cell device as a function of the front and rear active layers. (b) $J-V$ characteristics of devices SJ1, SJ2 (single junction solar cells) and T1 (tandem solar cell with best efficiency) under AM1.5 $100 \mathrm{~mW} \mathrm{~cm}^{-2}$ illumination. (c) J-V characteristics of device T2 (tandem solar cell with record FF) in the dark and under AM1.5 $100 \mathrm{~mW} \mathrm{~cm}^{-2}$ illumination. 
practically no absorption in the visible region, values of $k$ equal to 0 from $400 \mathrm{~nm}$ onwards, while the PFN displays a sharp narrow peak at $400 \mathrm{~nm}$.

In accordance with the $k$ values of the materials, we can see in Fig. $3 \mathrm{~b}$ that the absorptance of $\mathrm{MoO}_{3}$ in glass is negligible. If $1 \mathrm{~nm}$ of $\mathrm{Ag}$ is evaporated on top of the $\mathrm{MoO}_{3}$, a short broad peak appears at around $540 \mathrm{~nm}$ and finally when a thin film of PFN is spin-coated on top, to complete the ICL, a sharp peak at $400 \mathrm{~nm}$ appears together with the broad one observed for silver. On average, we were able to obtain a rather transparent interlayer as can be seen from the absorptance spectra of the ICL deposited on glass. Also, the PFN layer reduces the roughness of the $\mathrm{MoO}_{3} / \mathrm{Ag}$ layer to an RMS of $0.8 \mathrm{~nm}$ as observed by AFM (see Fig. S6, ESI $\dagger$ ).

We also constructed the following device structure: ITO/ $\mathrm{MoO}_{3} / \mathrm{Ag} / \mathrm{PFN} / \mathrm{Ag}$ and measured the $J-V$ response before and after UV illumination (see Fig. S7, ESI $\dagger$ ). The linear response suggests our ICL as a promising recombination layer. Using Kelvin Probe Microscopy (KPM) we measured the work function of the $\mathrm{Ag} / \mathrm{PFN}$ modified $\mathrm{MoO}_{3}$. The value of the work function obtained in air turned out to be $4.5 \mathrm{eV}$, very similar to the one measured under the same conditions for $\mathrm{ZnO}(4.3 \mathrm{eV})$. The work function values reported for $\mathrm{MoO}_{3}$ vary from $6.7 \mathrm{eV}$ for vacuum deposited $\mathrm{MoO}_{3}$ to $5.5 \mathrm{eV}$ for air exposed $\mathrm{MoO}_{3} \cdot{ }^{31}$ Thus, for our ICL, a high work function contrast is expected between the $\mathrm{MoO}_{3}$ and PFN layers which will further improve the performance of the tandem device. ${ }^{32}$
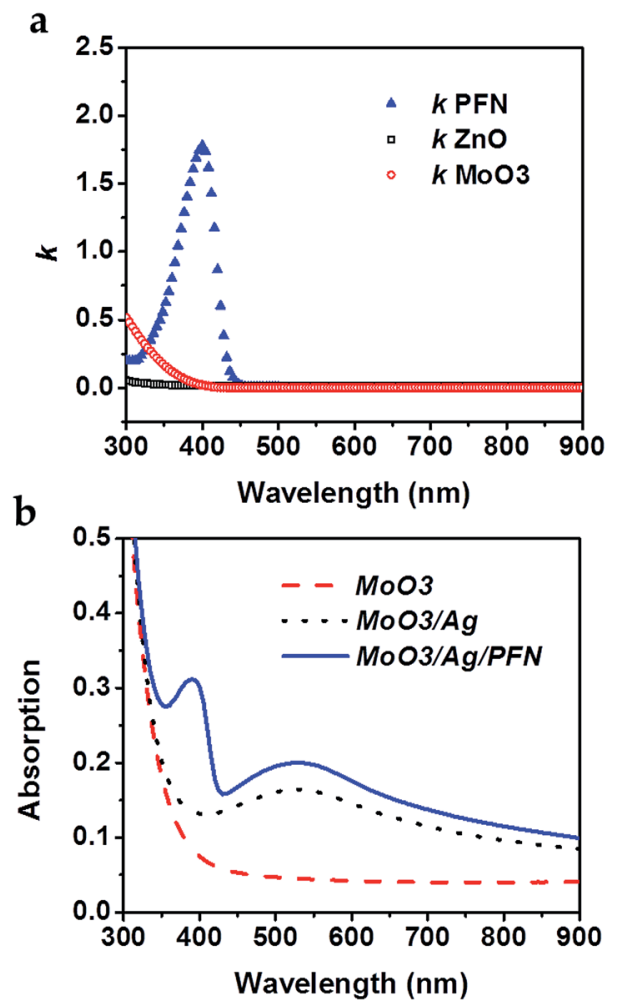

Fig. 3 (a) $k$ spectra of $\mathrm{ZnO}, \mathrm{MoO}_{3}$ and PFN electron transporting layers in the $300 \mathrm{~nm}$ to $900 \mathrm{~nm}$ range. (b) Measured absorbance of the different layers comprising the ICL on glass, $7 \mathrm{~nm}$ of $\mathrm{MoO}_{3}$ alone, $\mathrm{MoO}_{3}$ and $1 \mathrm{~nm}$ of $\mathrm{Ag}$, and finally $\mathrm{MoO}_{3} / \mathrm{Ag}$ and $7 \mathrm{~nm}$ of PFN.
Insight into the key role of the intermediate Ag layer to attain a large FF is provided by analysing a series of devices with varying nominal Ag contents in the ICL. The average FF of these devices increases from an initial value of $50 \%$ for the Ag-free ICL to a saturation value of $70-75 \%$ for nominal $\mathrm{Ag}$ contents of 0.5 $\mathrm{nm}$ and above, as can be seen in Fig. 4a. AFM imaging of test glass/ITO/ $\mathrm{MoO}_{3}(10 \mathrm{~nm}) / \mathrm{Ag}$ (0 to $2 \mathrm{~nm}$ ) samples was performed, revealing that the $\mathrm{Ag}$ is distributed within the ICL $\mathrm{MoO}_{3} / \mathrm{PFN}$ interface in the form of clusters scattered in a roughly uniform pattern over the $\mathrm{MoO}_{3}$ layer (Fig. 4b). The average nearest neighbour distance (NND) between $\mathrm{Ag}$ particles calculated from the images was found to decrease with increasing Ag content up to $1 \mathrm{~nm} \mathrm{Ag}$ nominal thickness, when the NND became negligible.

With no Ag in the ICL, electron-hole recombination is not complete, and therefore charges accumulate at the ICL intermediate interface, as evidenced by the S-shape in the corresponding $J-V$ curve (Fig. S8, ESI $\dagger$ ). Ag particles attract electrons and holes in the ICL and facilitate their recombination. This results in an enhanced $\mathrm{FF}$ for $0.25 \mathrm{~nm}$ nominal $\mathrm{Ag}$ thickness. For a nominal $\mathrm{Ag}$ content of $0.5 \mathrm{~nm}$ the average NND is $\sim 10 \mathrm{~nm}$ (i.e. the threshold for physical contact between particles has not been reached yet), but the FF has already reached its saturation

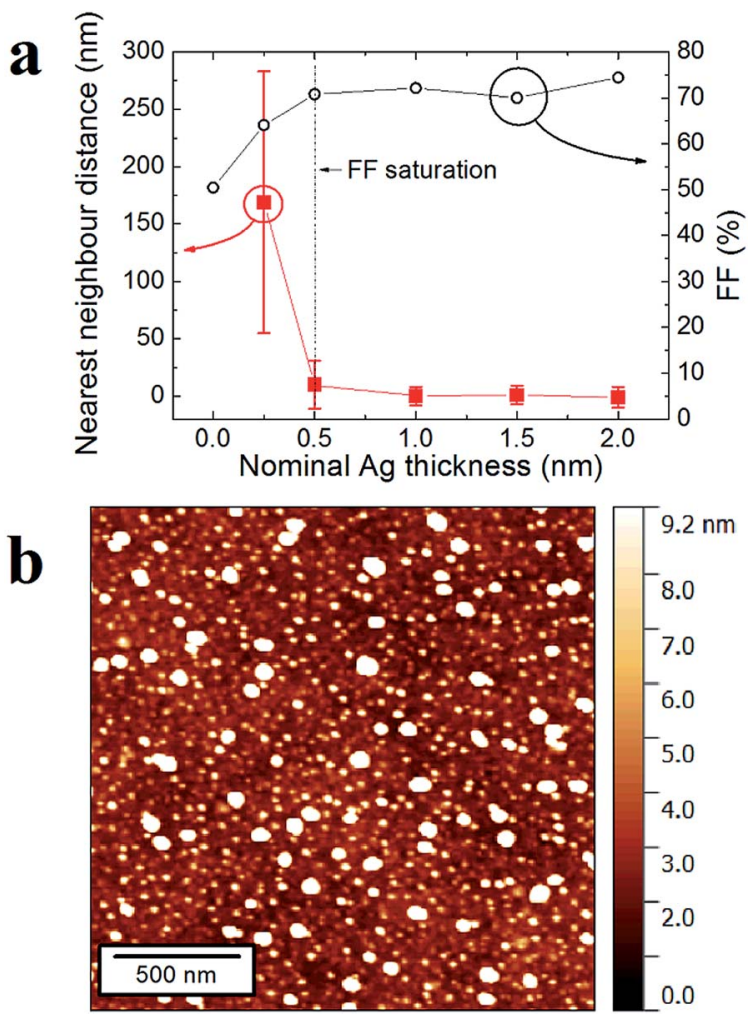

Fig. 4 (a) Average fill factor of tandem cells (black hollow dots) and average nearest neighbor distance between $\mathrm{Ag}$ particles in the $\mathrm{ICL}$ layer (red solid squares) as a function of the nominal Ag content in the $\mathrm{ICL}$. The vertical dashed line indicates the Ag content for which the FF saturates. Error bars indicate the standard deviations from the average. Solid connecting lines are a guide to the eye. (b) AFM image of a glass/ $\mathrm{ITO} / \mathrm{MoO}_{3} / \mathrm{Ag}$ sample with $0.5 \mathrm{~nm}$ nominal $\mathrm{Ag}$ thickness. FF is already maximized for the shown Ag particle density. 
value, implying that virtually all the recombination in the ICL happens via Ag particles. In other words, the maximum $\mathrm{FF}$ is achieved just below the percolation threshold for the formation of a long-range connectivity among the Ag clusters corresponding to a deposition of $0.5 \mathrm{~nm}$ of Ag. Beyond this point the $\mathrm{FF}$ does not seem to increase and further increment of the $\mathrm{Ag}$ content up to $2 \mathrm{~nm}$ does not imply any improvement in the performance of the cell.

In conclusion, inverted tandem PSCs using PTB7 active layers in both subcells with a $\mathrm{MoO}_{3} / \mathrm{Ag} / \mathrm{PFN}$ ICL were studied in this work. A PCE of up to $8.2 \%$ was achieved with front and rear layer thicknesses around $100 \mathrm{~nm}$ and $120 \mathrm{~nm}$, respectively. A FF of $76 \%$, never reported before for an organic tandem solar cell to the best of our knowledge, was also achieved. The total thickness of the ICL is below $20 \mathrm{~nm}$ but the PFN is demonstrated to be robust enough to avoid the degradation of the layers underneath. A very thin layer of Ag in the ICL is sufficient for maximizing the FF whilst maintaining a good ICL transparency. The PFN surface modification of the $\mathrm{MoO}_{3} / \mathrm{Ag}$ is found to reduce its work function, while maintaining the transparency and the robustness of the ICL. The low absorption spectrum covered by this tandem device appears to leave room for improvement by selecting subcells made of polymers with complementary absorptions.

\section{Experimental section}

\section{Device fabrication and materials}

PTB7 and PFN were purchased from 1-Material. PC71BM was purchased from ADS. A ZnO precursor, zinc acetate, was purchased from Sigma and $\mathrm{MoO}_{3}$ from Kurt Lesker. All the materials were used as received. For the single devices, a layer of ZnO or PFN was deposited by spin coating on top of the ITO covered fused silica substrate. ZnO was thermally annealed on a hotplate in air $\left(200^{\circ} \mathrm{C}, 10 \mathrm{~min}\right)$. The PTB7:PC71BM $(1: 1.5 \mathrm{wt}$ in $\mathrm{CB} ; 3$ vol\% DIO) layer was deposited by spin coating at $1800 \mathrm{rpm}$ inside a $\mathrm{N}_{2}$ filled glovebox. Finally, $3 \mathrm{~nm} \mathrm{MoO}_{3}$ and $100 \mathrm{~nm} \mathrm{Ag}$ layers were used to complete the devices. For the tandem devices, the front subcell was prepared as stated above using $\mathrm{ZnO}$ as an ETL. The ICL was fabricated by thermal evaporation of $7 \mathrm{~nm}$ of $\mathrm{MoO}_{3}$ and 0 to $2 \mathrm{~nm}$ of $\mathrm{Ag}$ followed by the spin coating of PFN $\left(1 \mathrm{mg} \mathrm{ml}^{-1}\right)$ inside the glovebox. The rear subcell was fabricated immediately after PFN deposition following the same steps as for the single junction cells.

\section{Device characterization}

$J-V$ curves were measured using a solar simulator under AM1.5 conditions (Abet Technologies, model Sun 3000). EQE values were measured using a QEX10 Quantum Efficiency Measurement System (PV Measurements). The light transmission spectra for the fabricated devices were recorded using an UV-visnear IR spectrophotometer (Lambda950, PerkinElmer). For the morphology and thickness studies, a Veeco Dimension 3100 AFM operated under ambient conditions in tapping mode was used. A scratching technique was used for accurate measurements of layer thicknesses. ${ }^{33}$ Kelvin probe measurements were performed using an ambient Kelvin Probe system (KP Technologies, Inc.). For the work function studies, an ITO-coated glass substrate was used since this measurement by the Kelvin probe technique requires a conductive substrate. The work function of the tip was calibrated using a gold surface.

\section{Acknowledgements}

We acknowledge the Ministerio de Economía y Competitividad which supported the work under grants MAT2011-28665, IPT120000-2010-29 and CSD2007-00046.

\section{Notes and references}

1 Y. H. Zhou, C. Fuentes-Hernandez, J. Shim, J. Meyer, A. J. Giordano, H. Li, P. Winget, T. Papadopoulos, H. Cheun, J. Kim, M. Fenoll, A. Dindar, W. Haske, E. Najafabadi, T. M. Khan, H. Sojoudi, S. Barlow, S. Graham, J.-L. Bredas, S. R. Marder, A. Kahn and B. Kippelen, Science, 2012, 336, 327.

2 B. Kippelen and J. L. Bredas, Energy Environ. Sci., 2009, 2, 251.

3 M. Helgesen, R. Sondergaard and F. C. Krebs, J. Mater. Chem., 2010, 20, 36.

4 C. J. Brabec, S. Gowrisanker, J. J. M. Halls, D. Laird, S. J. Jia and S. P. Williams, Adv. Mater., 2010, 22, 3839.

5 R. Betancur, P. Romero-Gomez, A. Martinez-Otero, X. Elias, M. Maymo and J. Martorell, Nat. Photonics, 2013, 7, 995.

6 S. B. Darling and F. Youc, RSC Adv., 2013, 3, 17633.

7 Z. He, C. Zhong, S. Su, M. Xu, H. Wu and Y. Cao, Nat. Photonics, 2012, 6, 591.

8 T. Yang, M. Wang, C. Duan, X. Hu, L. Huang, J. Peng, F. Huang and X. Gong, Energy Environ. Sci., 2012, 5, 8208.

9 Z. He, C. Zhong, X. Huang, W.-Y. Wong, H. Wu, L. Chen, S. Su and Y. Cao, Adv. Mater., 2011, 23, 4636.

10 L. Dou, J. You, J. Yang, C.-C. Chen, Y. He, S. Murase, T. Moriarty, K. Emery, G. Li and Y. Yang, Nat. Photonics, 2012, 6, 180.

11 (a) Y. Liu, J. Zhao, Z. Li, C. Mu, W. Ma, H. Hu, K. Jiang, H. Lin, H. Ade and H. Yan, Nat. Commun., 2014, 5, 5293; (b) Z. Zheng, S. Zhang, M. Zhang, K. Zhao, L. Ye, Y. Chen, B. Yang and J. H. Hou, Adv. Mater., 2014, 27, 1189.

12 T. Ameri, G. Dennler, C. Lungenschmied and C. J. Brabec, Energy Environ. Sci., 2009, 2, 347.

13 J. You, L. Dou, K. Yoshimura, T. Kato, K. Ohya, T. Moriarty, K. Emery, C.-C. Chen, J. Gao, G. Li and Y. Yang, Nat. Commun., 2013, 4, 1446.

14 D. Dou, J. You, Z. Hong, Z. Xu, G. Li, R. A. Street and Y. Yang, Adv. Mater., 2013, 46, 6642.

15 T. Ameri, N. Li and C. J. Brabec, Energy Environ. Sci., 2013, 6, 2390.

16 G. Dennler, M. C. Scharber, T. Ameri, P. Denk, K. Forberich, C. Waldauf and C. J. Brabec, Adv. Mater., 2008, 20, 579.

17 N. Li, D. Baran, G. D. Spyropoulos, H. Zhang, S. Berny, M. Turbiez, T. Ameri, F. C. Krebs and C. J. Brabec, Adv. Energy Mater., 2014, 4, 1400084. 
18 X. Guo, N. Zhou, S. J. Lou, J. Smith, D. B. Tice, J. W. Hennek, R. P. Ortiz, J. T. L. Navarrete, S. Li, J. Strzalka, L. X. Chen, R. P. H. Chang, A. Facchetti and T. J. Marks, Nat. Photonics, 2013, 7, 825.

19 B. Qi and J. Wang, Phys. Chem. Chem. Phys., 2013, 15, 8972. 20 (a) V. D. Mihailetchi, H. Xie, B. de Boer, L. J. A. Koster and P. W. M. Blom, Adv. Funct. Mater., 2006, 16, 699; (b) A. Gadisa, F. Zhang, D. Sharma, M. Svensson, M. R. Adnersson and O. Inganäs, Thin Solid Films, 2007, 15, 3126; (c) B. Ray and M. A. Alam, Sol. Energy Mater. Sol. Cells, 2012, 99, 204.

21 W. Chen, M. P. Nikiforova and S. B. Darling, Energy Environ. Sci., 2012, 5, 8045.

22 (a) M. D. Irwin, D. B. Buchholz, A. W. Hains, R. P. H. Chang and T. J. Marks, Proc. Natl. Acad. Sci. U. S. A., 2008, 105, 2783; (b) J. Yu, Y. Zang, H. Li and J. Huang, Thin Solid Films, 2012, 520, 6653; (c) T. Stubhan, M. Salinas, A. Ebel, F. C. Krebs, A. Hirsch, M. Halik and C. J. Brabec, Adv. Energy Mater., 2012, 2, 532.

23 Y. Yuan, J. Huang and G. Li, Green, 2011, 1, 65.

24 A. Martínez-Otero, X. Elias, R. Betancur and J. Martorell, Adv. Opt. Mater., 2013, 1, 37.

25 R. Betancur, A. Martínez-Otero, X. Elias, P. Romero Gómez, S. Colodrero, H. Miguez and J. Martorell, Sol. Energy Mater. Sol. Cells, 2012, 104, 87.
26 J. Jo, J.-R. Pouliot, D. Wynands, S. D. Collins, J. Y. Kim, T. L. Nguyen, H. Y. Woo, Y. Sun, M. Leclerc and A. J. Heeger, Adv. Mater., 2013, 25, 4783.

27 L. Lu and L. Yu, Adv. Mater., 2014, 26, 4413.

28 J. You, C.-C. Chen, Z. Hong, K. Yoshimura, K. Ohya, R. Xu, S. Ye, J. Gao, G. Li and Y. Yang, Adv. Mater., 2013, 25, 3973.

29 P. Romero-Gomez, R. Betancur, A. Martínez-Otero, X. Elias, M. Mariano, B. Romero, B. Arredondo, R. Vergaz and J. Martorell, Sol. Energy Mater. Sol. Cells, 2015, 137, 44.

30 (a) G. Dennler, K. Forberich, T. Ameri, C. Waldauf, P. Denk, C. J. Brabec, K. Hingerl and A. J. Heeger, J. Appl. Phys., 2007, 102, 123109; (b) N. Li, T. Stubhan, D. Baran, J. Min, H. Wang, T. Ameri and C. J. Brabec, Adv. Energy Mater., 2013, 3, 301; (c) N.-K. Persson and O. Ingana, Sol. Energy Mater. Sol. Cells, 2006, 90, 3491.

31 (a) S. Murase and Y. Yang, Adv. Mater., 2012, 24, 2459; (b) J. Meyer, S. Hamwi, M. Kröger, W. Kowalsky, T. Riedl and A. Kahn, Adv. Mater., 2012, 24, 5408.

32 (a) Y. Zhou, C. Fuentes-Hernandez, J.-W. Shim, T.-M. Khan and B. Kippelen, Energy Environ. Sci., 2012, 5, 9827; (b) J.-W. Shim, C. Fuentes-Hernandez, Y. Zhou, A. Dindar, T.-M. Khan, A.-J. Giordano, H. Cheun, M. Yun, S.-R. Marder and B. Kippelen, Adv. Energy Mater., 2014, 4, 1400048.

33 A. Martínez-Otero, F. Busqué, J. Hernando and D. RuizMolina, Nanoscale, 2010, 2, 1781. 